\title{
Competences between Labor Market and Higher Education through ESCO
}

\author{
Cristina-Vasilica ICOCIU ${ }^{1}$, Nicolae POSTĂVARU ${ }^{1}$, Mihnea Costoiu ${ }^{1}$, Tiberiu Gabriel \\ DOBRESCU ${ }^{1}$ and Cătălin-Ionuț SILVESTRU ${ }^{2}$ \\ 1) Politechnic University of Bucharest, Romania \\ 2) Bucharest University of Economic Studies, Romania \\ cvicociu@gmail.com,nicolae.postavaru01@gmail.com,mihnea.costoiu@upb.ro, \\ tibidobrescu@yahoo.com, catalin@ase.ro
}

The article presents a way to create university programs that will ease the recognition of qualifications using ISCO and ESCO. A new European model based on the American model for engineers created by the American Association of Engineering Societies is presented. The model has the advantage of being based on internationally recognized standards. It can be applied to higher and professional education, learning outcomes need to be established with the employers based on the ESCO. competences. The proposed model is easy to apply and understandable creating also a hierarchy of skills according to ISCO taxonomy. As the applied models will be created, for example for technical/ economy domain, they will be further presented. The application of these models and the need to recognize the qualifications lead to the need for automatic systems for monitoring and recording all formal, informal or non-formal learning activities throughout an individual's life and also his experience.

Keywords: Competences, ESCO, ISCO, ISCED, Learning Outcomes, Skills

Motto: "The mind is like a parachute... It only works if we keep it open." (Albert Einstein)

\section{1} Introduction

Keeping the curriculum up to date is today's necessity, because tomorrow it may no longer correspond to the requirements. What makes it so "perishable" in time? Why this race for modern programs? The answer can be found in the changing demands of the labor market.

How is this realized? Through the skills required from the graduate and implicitly the related learning outcomes. What are skills based on? On the new requirements of jobs, constantly modernized, demanding new skills. Therefore, we can say that modern technology is the engine for the skills, learning outcomes and implicitly the study programs. Technology is accelerating and what was good tomorrow is now changing and the day after tomorrow will be history. How to keep up with technology? Is it changing so radically? Can we keep up with technology and also respond to the demands of education in order to create a person who is adapted to the social requirements, to life in community and to personal interests? The answer is yes and we will continue to give it through a model of hierarchy of skills so that to think of changing only a small portion every year, the rest remaining the same. For this purpose we want to use ESCO, ISCED, ISCO and the logic they are created by.

\section{Materials and Methods}

\subsection{A new educational paradigm}

There has been a paradigm shift in education: the labor market makes demands and education honors them, in other words, we no longer "produce" what and how much education wants, but what the labor market needs and how much is needed on medium term; this is a marketing rule showing that education has become a market. Moreover, this change demonstrates that the former students have surpassed their teachers due to the technology development and can better anticipate the dynamic future of the society. The new paradigm entails that the market decides also on the content of education.

There are five steps in the new system in order to obtain a qualification:

- skills

- learning outcomes

- curriculum /study program

- certification of qualification 
- quality assurance

In order for this system to work, it has to be monitored and suited for the current requirements when released on the market.

School is no longer once for a lifetime, but for here and now, for 10-20 years from now there is adult education, as part of permanent education, which we have during life.

This is the second major paradigm that was changed compared to the past: education is lifelong, what you learn today is useful for tomorrow and tomorrow you shall learn for the next day.

This is something very hard to understand for the present generations, even impossible to imagine.

Lifelong learning shall take over a series of tasks of current education which shall be based mainly on creating the social person and knowledge together with development of personal qualities.

\subsection{A new monitoring system for vocational education and training}

For all the aspects mentioned in Section 2, monitoring instruments have been created: registers and related standards.

For the institutions from the labor market there is: (i) the Trade Registry (for the commercial entities), (ii) the Register of foundations and associations and (iii) the Register of governmental or mixed institutions.

For occupations there is the ISCO standard (International Standard Classification of Occupations), the most recent version ISCO08 (published in 2008), based on a taxonomic system [1]. The standard is implemented in all European countries, and not only, up to level 4 of classification, the unit group.

For skills and competences, in Europe, ESCO classification was created (European classification of Skills/ Competences, qualifications and Occupations) which shall be further detailed [2].

Each country has registers for occupational standards.

Each country has a national register for qualifications, which, according to the Council Recommendation of May 22, 2017
[3], should have a common format in all European countries, thus becoming a standard. Is comprises the standard field of ISCED (the International Standard Classification of Education) [4], the level of qualification (standard), description of the qualification based on learning outcomes and information related to quality assurance, as well as to the entity issuing the qualification (accredited institution).

There are also registers with information about those involved in the vocational education and training system. The educational institutions, the accredited ones, are registered. We can talk about the register of those enrolled in the formal education system, but also of the register of graduates from an education system. There are registers of specialists and various commissions that offer degrees and diplomas. Finally, there is also the register of quality assurance institutions and their commissions.

This monitoring and information system comprises:

- a system that manages occupations and their framework, for the EU - ISCO-08

- a "manager" of sectoral skills, it should be the professional associations, but there is no uniformity yet in this respect, at European level - ESCO

- a "manager" of occupational standards

- a "manager" of qualifications - the National Register

- a "manager" for quality, which conducts the audit of the vocational education and training providing institutions

- the register of those who are in training programs

- the register of specialists/ trainers classified on ISCED fields and qualification levels

- a register of graduates

- a register of education and training providers

This transparency of the system offers trust and, if accompanied by an employability register, it would lead to appreciating education at fair value. 
2.3. Standardization recognition and mobility factor

It can be said that this market made up of work and education "plays" around some standards that must be implemented so that we can speak of the desiderate of European treaty between countries: "free access to goods and services" [5]. In order to have the desired recognition and mobility, we must fully and correctly implement:

- ISCO-08 (2008 version), with its definitions and structure and understand that up to the unit group level, 4 digits, we cannot change anything without the agreement of the other international partners who adopted it. The Member States can have specific occupations, but, not so much new unit groups, different from the agreed standard.

- EQF (the European Qualifications Framework) - here Romania is in a good place and has approved the latest version proposed in May 2017 [3], by which learning outcomes were defined in terms of knowledge, skills, responsibility and autonomy of the qualified individual.

- ISCED 2013 - F, the international standard of education that establishes a hierarchy of the fields of study in education up to level three: detailed field. Member States may have new themes / specializations within a detailed field, but less new detailed fields. Detailed fields are unique by name until their amendment is decided and approved..

- Quality is ensured by including the national specialized institutions in the EQAR registers for higher education (The European Quality Assurance Register for Higher Education) and ECVET for vocational education and training (European credit system for vocational education and training).

- The documents, diplomas and diploma supplements and certificates are already standardized through the Europass portfolio.

Therefore, it can be said, that we are in a circle of "standardization" of education in relation to the labor market, as presented below (figure no. 1). Capitalist society means standards and procedures.

We want Romanian market to be prepared to adopt the standards, to adhere to them, to participate in their accomplishment, if possible, under no circumstances to avoid them, because the results would be disastrous on long term for higher and technical education.

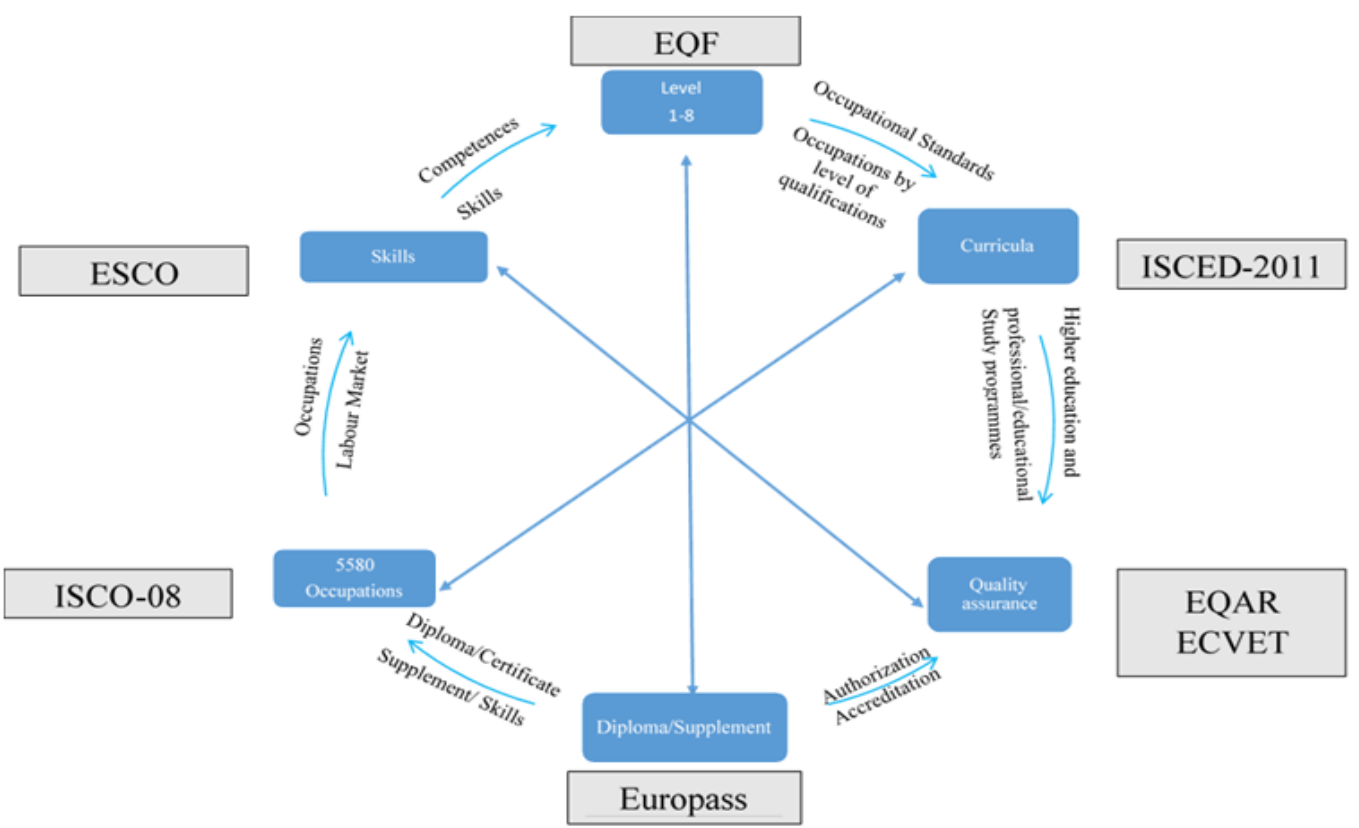

Fig. 1. Standardization of education and training in relation to the labor market (ESCO: A Bridge between Labour Market and Education Market [6]) 


\subsection{Taxonomy, common method for} connecting standards

What often connects these standards, through unseen threads, is taxonomy, that is, the system by which an element decomposes into others and each in turn into others and so on, a system the world itself is based on, which decomposes to its component particles, but which can also come together in the other direction and give the original as a whole, meaning it is a more physical than chemical decomposition.

As ISCO-08 is concerned, one can notice that it can be broken down into components called groups: 9 major groups, then major subgroups, minor and unit groups, which are internationally recognized (figure no. 2).

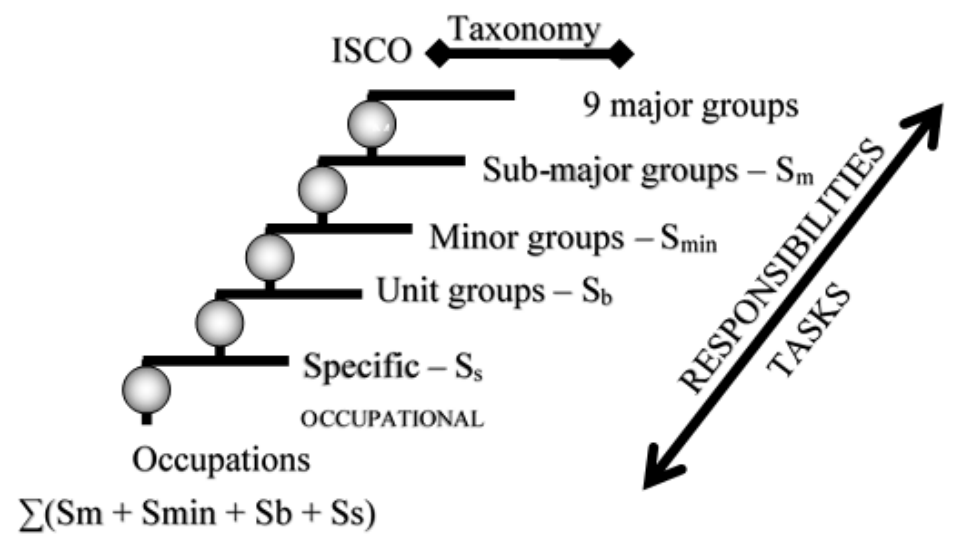

Fig. 2. Organization of ISCO Classification, seen with respect to tasks/responsibilities [6]

Each group is characterized by a number and its tasks and responsibilities, more general to the "higher" groups and more specific to the "lower" groups, the closer we are to the occupation. Finally, it can be stated that an occupation is a sum of tasks and responsibilities given by each figure/ group that it is comprised of.

For ISCED - 2013 [7], we notice the same taxonomic system organized by fields of study designated and internationally recognized as: broad, narrow, detailed fields and with subjects for specializations that represent areas of national interest (figure no. 3).

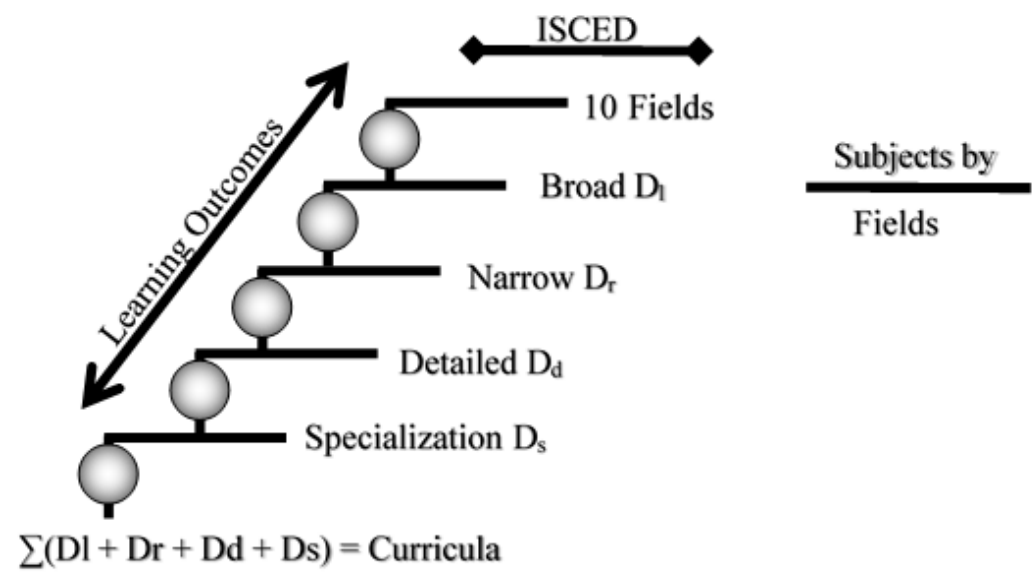

Fig. 3: Taxonomic organization of ISCED [6]

If these fields also have disciplines assigned (see the regulated professions above), it can be 
said that for any specialization we will have a sum of common disciplines, from the three fields that are common, up to the level of specialization; the curriculum becomes a sum of disciplines that represent each field and, at the same time, for example, connects specializations from the same detailed field. It is a fabric of domains and disciplines that gives the beauty of the surrounding reality, of the real nature.

In the new European construction, these disciplines are those that lead to key competences, on the one hand and/ or to the transversal ones, on the other hand.

These should help the individual understand the surrounding world, become better fixed in place and personally develop.

Just like the land, skills become more and more important on long term for one's career.

\subsection{ESCO}

So far, things would seem organized based on the two international standards (ISCO-08, ISCED), but as previously shown (figure no. 1), the system also includes one element: skills. These are at the basis of learning outcomes.

The essence of today's vocational education and training is represented by learning outcomes, or what an individual can actually do with the knowledge and abilities, skills acquired in the education and training process.

Is the European ESCO system a taxonomic system?

Could it be? Can we prove it? The authors think so.

The following figure (figure no. 4), shows such a possible system created by ranking the competences according to the model presented in the previous figure (figure no. 3), respectively core, fundamental, field related and specific skills.

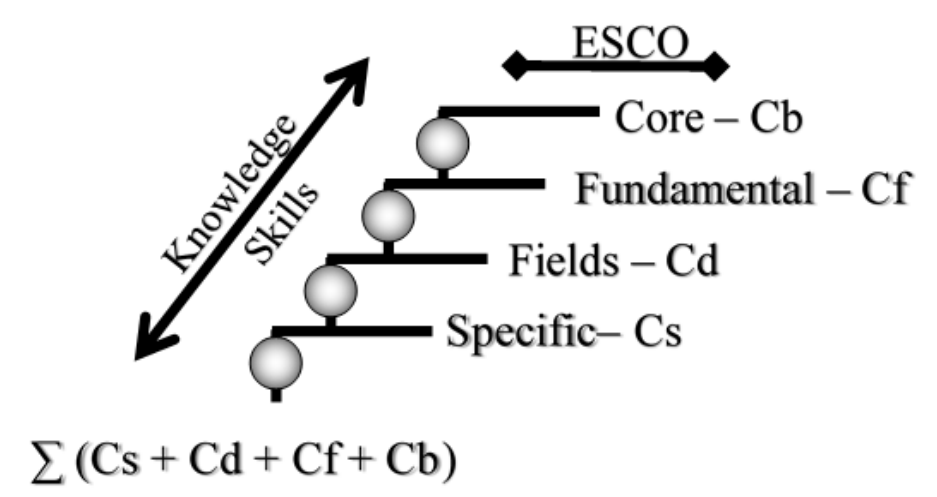

Fig. 4. Taxonomic organization of ESCO [6]

This would lead to the idea that the one who practices an occupation has different types of skills and competences, some specific to the occupation and others that are useful for other occupations or to solve the problems in the company or within the team, what we call personal, transversal or key skills and competences.
From the taxonomic model of the two standards, ISCO and ISCED, it results the ESCO skills and competences hierarchy, which is also a taxonomic structure (figure no. 5). This a the bridge ESCO created between the two standards representing education and labor market. 


\begin{tabular}{|c|c|c|c|c|c|}
\hline $\begin{array}{c}\text { ISCO - Taxonomic } \\
\text { system }\end{array}$ & & $\begin{array}{l}\text { Tasks } \\
\text { ISCO }\end{array}$ & $\begin{array}{c}\text { Competence/ } \\
\text { skills } \\
\text { hierarchy }\end{array}$ & $\begin{array}{c}\text { Competence/ } \\
\text { skills } \\
\text { ESCO - } \\
\text { hierarchy }\end{array}$ & $\begin{array}{c}\text { Notes } \\
\text { ISCED fields }\end{array}$ \\
\hline & $\longrightarrow$ Major group & General & EQF level skills & EQF level & \\
\hline & Sub-major group & Fundamental & Fundamental & Fundamental & Broad \\
\hline & $\rightarrow$ Minor group & Basic & Basic & Basic & Narrow \\
\hline & $\longrightarrow$ Unit group & Field related & Field related & Field related & Detailed \\
\hline & $\longrightarrow$ Occupations & Occupational & Specific & Specific & \\
\hline
\end{tabular}

Fig. 5. ISCO - ESCO - a common hierarchy

In comparison with this system, the authors In the end, it will be in the shape of a pyramid, propose a European system focused on ISCO but built according to another calculation tasks and responsibilities and the hierarchy of model based on the layout shown below skills/competences according to the (figure no.6).

taxonomic model.

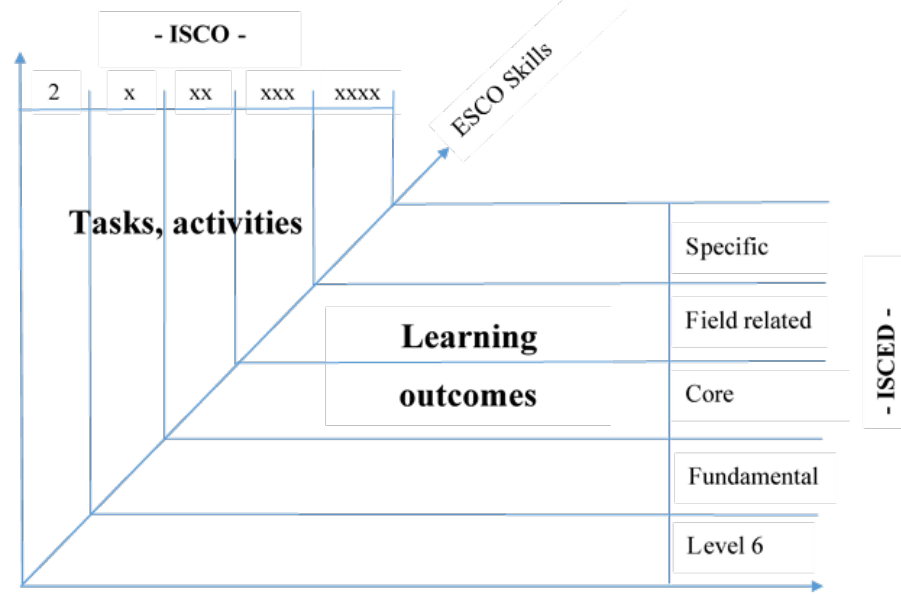

Fig. 6: Example of skills/competences hierarchy [6]

In this proposed system, ISCO major group indicates the level of NQF qualification, the rest falling under the taxonomic systems, as previously presented (figures no. 2, 3 and 4). The authors propose a way of designing the study/ qualification programs that permanently respond to the demands of the labor market, expressed through tasks and responsibilities and concluded by up-to-date skills and concrete learning outcomes, beneficial to the individual.

\section{Study Programs - Recognition of Qualifications}

3.1. Construction of study programs

Our inspiration comes from USA, where the American Association of Engineering Societies developed in 2015 a skills model [8] as a basis for designing international programs (figure no. 7). 


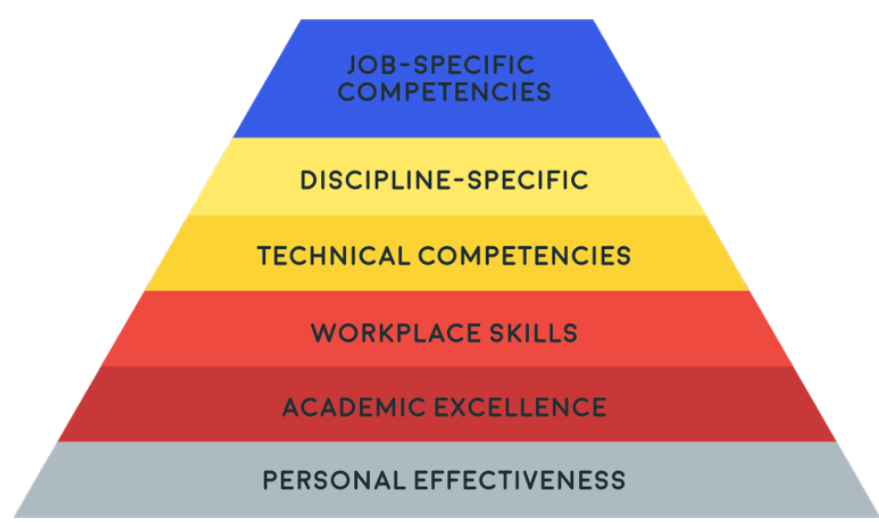

Fig. 7. USA skills model (source: [8])

Thus, a pyramidal system, similar to the American one, is created (figure no. 8), but according to the international standards model from the table shown in figure no. 9 (figure no. 9). One can notice that it is the same pyramid, only that we have to insert skills/ competences from ESCO, ranked by qualification levels and ISCO groups.

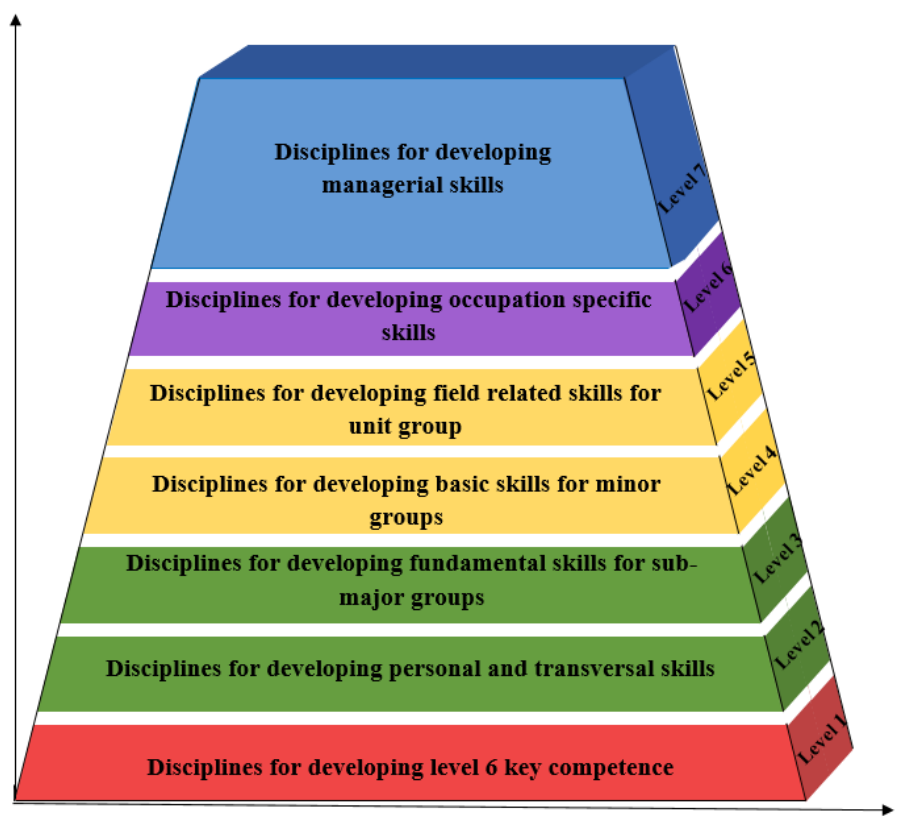

Fig. 8. Model for designing higher education study programs

This is the point where one can talk about the hierarchy of skills/ competences, according to ISCO and ISCED, and then about the associated learning outcomes.

To make the work easier the authors propose in the next table (figure no. 9) a two-part system:
- a common part, at European level, for the development of European programs for core (basic)/ fundamental/ field related levels and

- a specific part, through national programs, for the development of specific fields/ disciplines. 


\begin{tabular}{|c|c|c|c|c|c|}
\hline $\begin{array}{c}\text { Occupation } \\
\text { Qualification }\end{array}$ & Tasks & $\begin{array}{c}\text { Competence/ } \\
\text { Skills }\end{array}$ & $\begin{array}{c}\text { Learning } \\
\text { outcomes }\end{array}$ & Disciplines & Program \\
\hline $\mathrm{x}$ & & & & \\
\hline $\mathrm{xx}$ & & hierafchy & & \\
\hline $\mathrm{xxx}$ & & base & common at & European level \\
\hline $\mathrm{xxxx}$ & & & & \\
\hline $\mathrm{xxxxxx}$ & & & national level to correlate \\
\hline
\end{tabular}

Fig. 9. ISCO - ISCED - common base programs

Thus, ESCO becomes an instrument as it was initially presented: of establishing a minimum European skills/ competences sets necessary for the recognition of qualifications (about 70$75 \%$ of those an applicant has in its portfolio at employment), which are locally complemented by another set given by the specifics of the qualifications in the respective region and university/ training supplier (about $25-30 \%$ ).

Thus, one can talk about internationalization, mobility for all, digitization, innovation, and support of young people's employability in the European common labor market.

Automatic recognition means that an institution or a machine can answer two questions:

1. What percent of the CV-x\% - skills / learning outcomes / experience corresponds to the job requirements.

2. What percent - y\% - except for compensatory measures, you can take to have the $\mathrm{CV}$ recognized and occupy the proposed job.

3. When $\mathrm{x} \ldots \ldots .>100 \%$ we have automatic recognition.

For this we must also understand the difference between learning outcomes/ skills/ experience, certified and recognized.

Thus to make the difference between the certificates issued by an authorized institution, legally entitled to do so and recognition that may be institutional or formal.

Only the institutional certified qualifications will be automatically recognized.

Through the proposed model, the learning outcomes and related competences up to the unit group level can be automatically recognized because they have the same common source in ISCO and lead to common areas in ISCED.

This means that the recognition remains to be done only for the learning outcomes related to the specific skills and competences at the occupation level, which is much simpler and easier even for the applicant.

Thus, the compensatory measures are fewer and we thus reach ESCO's goal: to support education and the labor market to better harmonize between supply and demand.

What we need to learn:

- a qualification leads to practicing at least one specific occupation,

- experience can lead to practicing several occupations, if certified,

- a qualification plus experience plus continuous training is the future for us to secure a job tomorrow.

What are we missing today? The hierarchy of ESCO skills/ competences and the curriculum designed based on such skills, hierarchically, in pyramid form, starting with the common skills which bring us closer to everyone in Europe and then moving to the specific ones, depending on the country or region, industry, activity, qualification level.

The labor market can be correlated with the education market if ESCO undertakes its initial tasks and is further supported at European and local level.

\subsection{The future of higher education}

Many people question what higher education will be like after 2025-2030.

In the spirit of those presented and mentioned by the World Economic Forum, that higher 
education is one-step ahead of school in terms of demand; it is shaped to be organized according to the following system:

- A short-term general higher education (23 years) organized on ISCED broad fields. In the future, due to the changes in the economy and the speed they occur, it will be difficult for a young person to wish for a narrow specialization because, until graduation, the student may not know if that specialization exists anymore.

This short education will include:

A. On the one hand, basic - transversal competences and related disciplines: for example, the 10 soft skills [9]:

1. Cognitive Flexibility - The ability to generate or use different sets of rules for combining or grouping $\mathrm{t} 10$. Cognitive

2. Complex Problem Solving Developed capacities used to solve novel, ill-defined problems in complex, real-world settings.

3. Coordinating with Others Adjusting actions in relation to others' actions.

4. Creativity - The ability to come up with unusual or clever ideas about a given topic or situation, or to develop creative ways to solve a problem.

5. Critical Thinking - Using logic and reasoning to identify the strengths and weaknesses of alternative solutions, conclusions or approaches to problems.

6. Emotional Intelligence - Being aware of others' reactions and understanding why they react as they do.

7. Judgement and Decision Making Considering the relative costs and benefits of potential actions to choose the most appropriate one.

8. Negotiation - Bringing others together and trying to reconcile differences.

9. People Management - Motivating, developing and directing people as they work, identifying the best people for the job.

10. Service Orientation - Actively looking for ways to help people

These are similar to the American system presented for engineers, based on personal, academic and workplace skills and competences.

They will be generalized for any graduate and differentiated by qualification levels.

B. Fundamental competences as a result of successfully completing the fundamental disciplines, each identified for the 10 ISCED fields, established in accordance with the employers, but with a reduced amending time rate, for example, 1:10/15 years.

C. After graduation, the individual will receive a certificate stating his fundamental training and the chosen field; with the exception of the regulated professions.

On this basis, and foundation a new career through school will be built, depending on each person's skills and the market requirements.

The short cycle graduate will have to choose between several fields, to build on the fundamental one, through specialized study programs.

- Specialized higher education

After the short cycle, there will be a training/ specialization period lasting 1-2 years, in the desired field, in accordance with the fundamental field, organized in two stages:

C1. Field related training, with the duration not exceeding 60 credits.

In time, this can be changed/ updated at intervals of 5 years. The individual will be able to change his field of activity and/or will be retraining several times in his life, depending on skills, market, desires, and other personal requirements. Through recognition, this retraining period will be reduced to maybe 30 ECTS credits or less.

This system is especially useful for young people, with an attraction for a fundamental field, but not knowing what narrow field to choose, and "fumbling" through society until they find the one they like. Along with appropriate practice, this will usually take the shape of formal training.

\section{C2. Specialized training}

The young graduate, who holds the 150-180 ECTS credits, will be able to choose between 
specialized study programs for the desired specialization.

Specializing courses will be attended at the faculty level in a formal or post-university system of continuous training, through shortterm specializing courses, $15-30$ credits; this is shown in short in the following figure (figure no. 10).

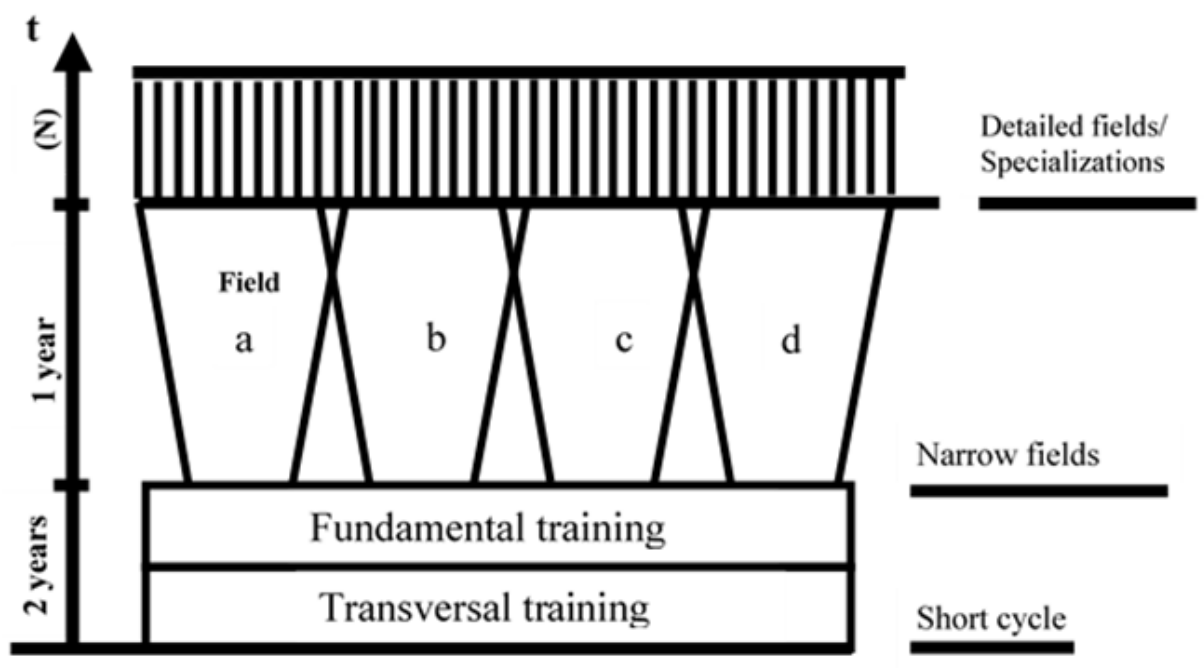

Fig. 10. Future of training [6]

The duration of these programs can be reduced in time, by recognizing competences and learning outcomes acquired previously or through experience.

The training will no longer be for specialized occupations, but for specialized learning outcomes (World Economic Forum 2016), which will have a wider utility. The role of experience will increase decisively at the expense of specialized theoretical training.

Based on those presented herein, the authors' model on the hierarchy of competences and the development of higher education study programs - the pyramid of vocational education and training presented (figure no. 8). It is also a response to the American model.

\section{Conclusions}

Education will adjust to technology; knowing how to think, search, and create will be tomorrow's requirements and goals. The computer will replace bureaucracy. Information will be available in the cloud, it will be sufficient for everything we want, but we will need to know how to access it. The care for people, environment, and resources will increase and we pray that violence will be replaced by communication. That is why we will have to understand the role of personal/ transversal skills and competences taught from an early age in society, according to the level of education and understanding of each person. Many will ask themselves what skills God gave them, and will pray to find the way God set for them, which will be the hardest and most valuable thing in the future.

\section{References}

[1] International Standard Classification of Occupations, 2008

[2] ESCO - https://ec.europa.eu/esco/portal

[3] COUNCIL RECOMMENDATION of 22 May 2017on the European Qualifications Framework for lifelong learning and repealing the recommendation of the European Parliament and of the Council of 23 April 2008 on the establishment of the European Qualifications Framework for lifelong learning (2017/C 189/03)

[4] International Standard Classification of Education (ISCED), 2011

[5] Treaty on the Functioning of the European Union, 2012

[6] C. V. Icociu, N. Postăvaru, T. G. Dobrescu, C. I. Silvestru, ESCO: A Bridge between Labour Market and Education Market, Proceedings of The 2nd International Conference on Advanced 
Research in Teaching and Education, 2019

[7] International Standard Classification of Education: Fields of Education and Training 2013

[8] Employment and Training Administration United States Department of Labor (ETAUSDL) www.doleta.gov -
Engineering Competency Model - May 2015

[9] Work Economic Forum (2016) The Future of Jobs: Employment, Skills and Workforce Strategy for the Fourth Industrial Revolution, Available at: http://www3.weforum.org/docs/WEF_Fu ture_of_Jobs.pdf

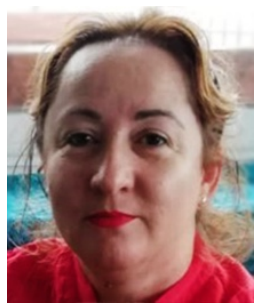

Cristina Vasilica ICOCIU graduated the Faculty of Law in 1996 with a Bachelor diploma at the Alexandru Ion Cuza Police Academy. She holds a Master diploma since 2001 and a $\mathrm{PhD}$ diploma since 2010, both in administrative sciences at the National School of Political Studies and Public Administration. In this respect she has an extensive experience in central administration field, mainly in education and research field, where she has occupied various management positions, from General Manager to Deputy Secretary-General, but also at government level, as councilor to the Vice prime-minister on economy and business environment.

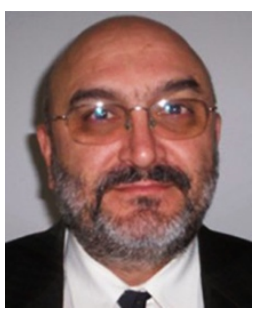

Nicolae POSTĂVARU is a professor, specialized in the field of investment and construction management, with more than 35 years of experience in business, education and research, has developed, coordinated and implemented international projects, managing to attract founding of more than 300 million euros in the education and training system. His activity so far has been led by the following constant areas of interest: lifelong learning, qualitative mentoring and effective strategies for human resources development.

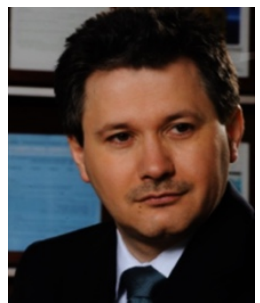

Mihnea Cosmin COSTOIU graduated from the University POLITEHNICA of Bucharest, the Economical engineering specialization, in 1996, and continued his studies in the same field with a master's degree. Between 2002 and 2003 he followed postgraduate specialization studies, at the National Defence College (Ministry of National Defence, Romania), followed by courses in the field of higher education management, at the Academy of Economic Studies of Bucharest (2011). Between 1997 and 2000 he lectured as an associate professor within the Academy of Economic Studies of Bucharest and the National School of Political and Administrative studies of Bucharest, and, since 2005, at the University POLITEHNICA of Bucharest - where he holds courses and seminars in human resource management, organizational management, international and EU funded project management, engineering or industrial projects. He is also the rector of the University POLITEHNICA of Bucharest. His participation in international conferences has brought him worldwide recognition. He has been awarded more than 70 prizes and golden medals and is also the winner of 11 international patents.

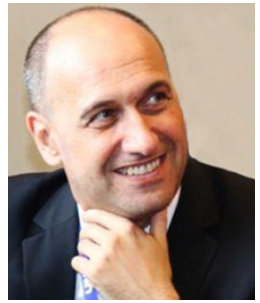

Tiberiu Gabriel DOBRESCU is Head of Robots and Manufacturing Systems Department, Industrial Engineering and Robotics Faculty, at Politehnica University of Bucharest. He has been involved, as researcher, in a number of projects with European funding relating to adult education sector. He is also member in several working groups as European level (such as EQF AG, ESCO) as well as in various working groups and committees at local level 
involving adult education and training, higher education and professional development. Mr. Dobrescu is the author of various scientific papers, articles and publications on engineering as well as related to adult education sector.

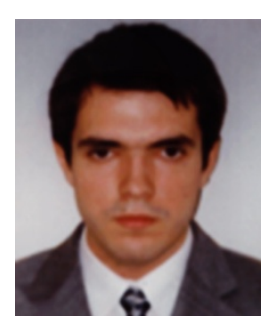

Cătălin Ionuț SILVESTRU is associate professor in Economic Informatics and Cybernetics Department, Academy of Economic Studies of Bucharest. He received his $\mathrm{PhD}$ in the field of Economic Informatics at the Academy of Economic Studies. He is a member of INFOREC professional association, Project Management Romania association, ACM, IEEE and others. He has one invention and one prototype approved. His work focuses on the programming, robotics, information system, e-learning, long life learning, and project management, building management system, software application, integrated management systems and human resources development. His research experience is consistent as Project Manager of 7 research projects won by competition in National contests and 9 projects won by competition in International contests. He published over 40 articles in journals and magazines in computer science, informatics, e-learning, project management and long life learning fields, over 30 papers presented at national and international conferences, symposiums and work-shops and he was member in over 38 research projects. 